protect personnel during this operation, a number of interlocking devices are incorporated so that the container cannot be opened until the source is retracted into the safe position.

The programme of work envisaged with the radiation equipment includes both research and development. In the first instance, the effects of irradiating plastic materials are being studied in detail because it has already been shown that very useful changes can be produced in materials such as polyethylene, rubber and silicones.

At the same time, fundamental research is being undertaken into the mechanism by which radiation interacts with matter, and includes such problems as the irradiation of solutions, effects of inhibitors or protective agents, and the dependence on temperature of radiation-induced chemical changes. The investigation of radiation effects in materials may be considered as a new branch of scientific study involving close collaboration between chemists, physicists and biologists. Many of the effects observed are very novel, and their elucidation should provide not only a basis for further advances in radiation techniques and applications but also may well throw light on basic chemical reactions. The number of problems open for investigation is embarrassingly large, and collaboration with other organizations and research associations interested in the study or application of radiation methods is essential if rapid advances are to be made in this exciting new field.

\title{
THE MINISTRY OF AGRICULTURE, FISHERIES AND FOOD
}

\section{WILSON REPORT}

$I^{N}$ December 1954 an independent Commitiee, that is, not an inter-departmental one, was set up to review the ex-Headquarters organization of the Ministry of Agriculture and Fisheries, to which has now been added the remnants of the Ministry of Food, making it the M.A.F.F. The report of this Committee has recently been published* and, from the name of its chairman, Sir Ayrton Wilson, is being referred to as the Wilson Report. Anyone desirous of forming a clear view of the multitudinous activities of this Ministry and how they impinge on the farmer cannot do better than read this report. Although conforming to the usual style of such reports, with short numbered paragraphs, it is extremely lucid and readable and displays throughout its hundred pages the extreme thoroughness with which the members of the Committee have carried out their difficult task.

The Committee was asked "to consider generally whether the organization is best adapted to secure efficient and economical performance of the functions of the Ministry", to which the Committee's reply is summarized as, "It could certainly be better adapted"; whether "there was undue complexity, over-specialization, or overlapping", to which the reply is, "Yes! there is" ; and whether "there was duplication and unnecessary interference with the work of local authorities", to which the reply is, "Little or no evidence of this". In addition to these three questions, the Committee was asked to survey the remaining organizations of the Ministry of Food and also to examine carefully the methods for dealing with the acquisition, management and disposal of land by the Minister and with the preparation of cases for consideration under the Agricultural Act of 1947 and the Agricultural Holdings Act of 1948. Because these cases impinge so directly on the rights and livelihood of individual citizens, the Minister evidently felt it necessary, in view of public criticism, to have existing procedures reviewed by an independent body. Comparatively minor improvements are put forward.

The report concludes with no less than seventyeight main recommendations which, if put into effect, would result in savings approaching a thousand in staff and $£ 1,000,000$ in salaries, travelling expenses

* Report of the Committee appointed to review the Provincial and Local Organtzation and Procedures of the Ministry of Agriculture, Fisheries and Food. Pp. vi+108. (Cmd. 9732.) (London: H.M. Stationery Office, 1956.) 4s. $6 d$, net. and general overheads. There would be additiona savings on premises difficult to estimate accurately in advance. With the present Government committed to some reduction in national expenditure, it is evident that many of the recommendations of the Wilson Committee are likely to be implemented and they are now being considered by the County Agricultural Executive Committees as well as by the organizations concerned. Clearly it is not possible here to give an adequate summary of the voluminous report and its many findings ; but an attempt will be made to select some of the major points.

Apart from its headquarters staff, the Ministry has no less than thirty-two organizations which can be divided into six major groups, with a staff of 8,500 , and twenty-six smaller groups with about 1,500. The total annual cost is just under $£ 10$ million. The major groups are the County Agricultural Executive Committees, the National Agricultural Advisory Service, the Agricultural Land Service, the State Veterinary Service, Fatstock-Marketing, and the National Milk Testing Service. Examples of the minor groups are the Agricultural Lime Department, Land Drainage and Water Supply, the Rodent Inspectorate and the Insect Inspectorate. The organizations work within twenty-two different sets of boundaries-a fact which, in itself, indicates the probability of frequent lack of co-ordination.

Before planning some pruning, streamlining and regrouping of these numerous bodies the Committee first pointed to certain weaknesses, abnormalities and dangerous tendencies, and then laid down some desirable principles. Unlike most government departments, the Ministry of Agriculture and Fisheries has created its own local authority in the form of the County Agricultural Executive Committees and invested them with both advisory and executive duties. For the executive work, the Ministry has made much use of technical and professional staff instead of keeping to the usual practice of using administrative staff. The numerous separate organizations had the dangerous tendency of getting away from team-work altogether. "The Ministry's local organization is riddled with divided loyalties and dual control." The basic principles which, in the opinion of the Committee, ought to be followed are : first, the operations and methods of a Ministry should be supported by a broad body of public 
consent ; second, that" clear " clean" is printed in the report) lines of command should flow from the centre to the farthest out-station, leaving no officer in doubt about his responsibilities or about who is his superior officer; third, the insidious growth of "perfectionism" must be avoided, for example, the tendency to develop a function beyond reasonable limits and regardless of cost ; fourth, the organization and procedure must permit effective control of finance -not merely precise audit but provision for thorough preview of proposed outlay.

The most important local body is the County Agricultural Executive Committee, particularly as the National Agricultural Advisory Service county staff is closely associated with it. The proposals of the Wilson Committee regarding the County Agricultural Executive Committees can be taken as illustrative of the lines along which reorganization is envisaged. At the time of the Ryan Committee set up in 1949 with somewhat similar terms of reference, four of the main jobs of the County Agricultural Executive Committees were their responsibility for production targets, conduct of the Farm Survey, supervision of backward farmers, administration of trading services and subsidies. Since then, however, targets have gone, the survey has practically ceased, supervision cases are trivial in number; on the other hand, the country has continued to pay large sums in grants and subsidies. It is clear, therefore, that there must now be concentration on technical development to ensure higher and higher efficiency if the subsidies are to be justified. Technical development must in future be the first and primary duty of the County Agricultural Executive Committees, working in close co-operation with the National Agricultural Advisory Service. A second function would be to act as local adviser to the Minister.

Where State action affects the liberty and livelihood of the individual farmer, thegre is also need for local consideration of appeals against decisions of Civil servants dealing with routine work such as grants and subsidies. Other local problems, such as the completion of rabbit clearance and the use of land for particular purposes, can be dealt with by the same body. The Wilson Committee accordingly recommends that the future structure of a County Agricultural Executive Committee should be a Main Committee to concentrate on technical work and advice to the Minister, but delegating the other functions mentioned to a tributary body called the Executive Panel. The delegation of duties should be complete, the Main Committee merely receiving a regular report from the Panel. The word 'Executive' would in future be omitted from the name of the County Committee so that it would become the County Agricultural Committee. The chairmen of these Committees, preferably younger men than at present and with a broad outlook and constructive ideas, would meet regularly in the different regions and also have close links with the Minister through liaison officers. With a few exceptions, such as East and West Suffolk which would probably be made into one unit, the County Agricultural Committees would remain on the present county basis.

The report next deals with the routine executive and trading work no longer to be done by the County Agricultural Committee. For these the unit of area suggested is again the administrative county, except that there would be more amalgamations of smaller counties, for example, combining Cumberland with
Westmorland, and Bedfordshire with Hertfordshire. In this way the existing sixty county units would be reduced to not more than forty, each with its "Divisional Executive Office". Besides doing the routine work mentioned, the Divisional Executive Office would provide clerical staff for the County Agricultural Committee and have attached to it the Area Milk Organization, the Lime Inspectorate, Pest Officers, etc. The office would be under the control of a senior member of the Civil Service Executive Class. The executive divisions ( $=$ counties or amalgamated small counties) would be grouped into Regions with boundaries, for the most part, coinciding with the present Standard Government Regions. In the north and in the south-east, com. binations of two regions would reduce the ten Government Regions to eight Agricultural Regions. Wherever possible, the Ministry's Regional Staff would be centred in the standard regional "capital", such as Cambridge. Here there would be in command an administrative, not a technical, officer with the rank of Assistant Secretary. He would be the Ministry's chief official and representative in the region, and would supervise all regional staff comprising twelve separate services such as the National Agricultural Advisory Service, Fatstock Marketing, Defence. The technical staff at regional level, though under the general direction of the Controller, would retain the right of direct access to their superiors at the Ministry on technical matters.

Regarding the twelve services at the regional centre (four of them at county-level also), numerous recommendations are made, some of considerable importance. The National Agricultural Advisory Service would have lost most of, but not quite all, its non-advisory functions. It is also proposed that it should hand over to the Veterinary Service its Milk Production Officers who, "for all practical purposes are not advisory officers nor does the present nature of their work require them to be milk production specialists-- they are scarcely concerned until the milk is in the pail". The number of Farm Machinery Specialists is also thought excessive and it is recommended that there should be one at each regional centre and one in large arable counties. In the case of horticulture, the recommendation is that the regional specialists should be reduced in number and sent to front-line work in the counties, where they should be able to do more effective advisory work. The Wilson Committee very pertinently and rightly directs attention to an outstanding weakness of the National Agricultural Advisory Service's structure (which some, including the present writer, pointed out even before it had started to function), that the 'key' man of the service, the District Officer, could only get promotion by "being withdrawn from front line work". An important addition to the Service is recommended owing to the proposed reorganization of the present Agricultural Land Service: it is that a specialist estate management section should be formed at regional level. The land service, it is suggested, should shed its extraneous nonprofessional duties and become a compact body of highly qualified land agents. Its local organization would be based on the new divisions and obtain its clerical staffs and common services from the Divisional Executive Offices. A somewhat similar reorganization is proposed for the Veterinary Services.

A long chapter of the report deals with "Milk Administration". "We have found it fascinating but extremely complicated." The main recommendation 
is that the National Milk Testing Service with its 350 staff should be disbanded and its work handed over to the Milk Marketing Board and the Veterinary Inspectorate. It was always difficult to see any real justification for the existence of the National Milk Testing Service.

In conclusion, one feature of the reorganization planned by the Wilson Committee may be pointed out which will please those who, like the writer, continue to maintain that the advisory and educational services should never have been divorced and should be 'remarried' as soon as possible. The County Agricultural Committees will remain based, in general, on existing counties and will have, as their chief concern, technical development and advisory work. It would be a small and comparatively easy step to add to these duties the responsibility for agricultural education in the counties. A great accession of strength would accrue to both services and further large economies in man-power and expenditure could be achieved together with greatly increased efficiency.

\section{STRUCTURE OF VITAMIN $B_{12}$}

\section{BY DR. DOROTHY CROWFOOT HODGKIN, F.R.S., JENNIFER KAMPER, MAUREEN MACKAY and JENNY PICKWORTH \\ Oxford}

\author{
KENNETH N. TRUEBLOOD \\ Los Angeles
}

AND

\author{
JOHN G. WHITE \\ Princeton
}

QINCE our communication in August 1955 1 , we $D$ have carried our refinement of the structure of vitamin $\mathrm{B}_{12}$ a critical stage further. Four more calculations of the electron density distribution have been made, one for the wet $B_{12}$ crystals, two for airdried $B_{12}$ crystals and one for the hexacarboxylic acid.

In Fig. 1 are shown the electron density peaks over all the atoms of the $B_{12}$ molecule as it appears from our present calculations in the wet crystals.

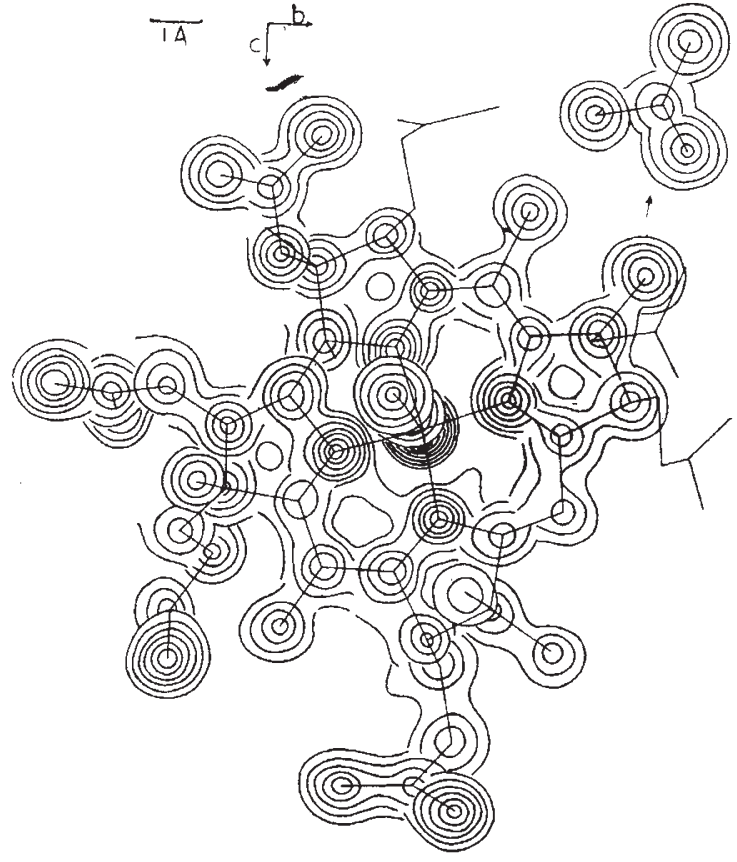

(a)
These peaks are rather lower than those observed for the hexacarboxylic acid owing to the smaller number of $X$-ray reflexions given by "the larger molecule in proportion to its size. But they serve to show the relative positions of all the atoms in space of this very complex molecule within probably as little as $0 \cdot 3 \mathrm{~A}$. Similar evidence has been obtained for air-dried $\mathrm{B}_{12}$; for both crystals the reliability indices in the latest structure factor calculations, $36 \cdot 1$ and $30 \cdot 6$ per cent, respectively, are now low

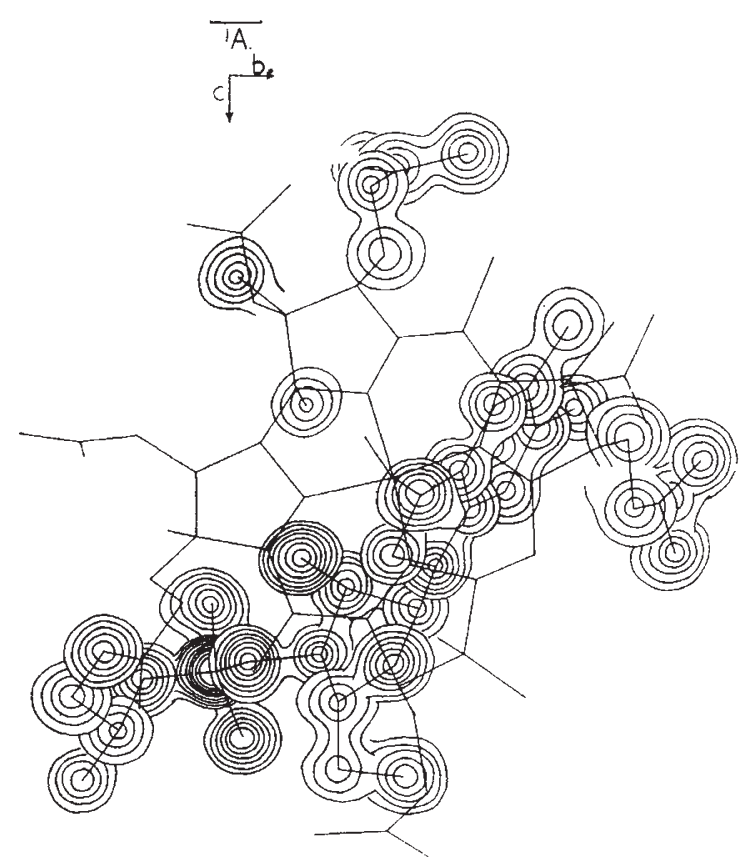

(b)

Fig. 1. Electron density-levels from the three-dimensional electron density distribution for wet $\mathbf{B}_{12}$ crystals, calculated with terms

Here, and in Fig. 4, the contours are drawn in the sections of the calculated distribution parallel with the $a$ plane, passing at or near the atomic positions. Owing to the complexity of the molecule, complete contours for every atom are not given and the figure is divided into two parts. (a) shows the cobalt-containing nucleus and cyanide group ; (b) the benziminazole, sugar, phosphate and propanolamine groups, the side chains being divided between the two. The acetamide chain on ring $B$ is inset. The contour interval is 1 e/A. ${ }^{3}$ 